\title{
The Study of Otoacoustic Emissions and the Suppression of Otoacoustic Emissions in Subjects with Tinnitus and Normal Hearing: An Insight to Tinnitus Etiology
}

\author{
Lucieny Serra ${ }^{1}$ Gabriela Novanta ${ }^{1}$ Andre Lopes Sampaio ${ }^{1}$ Carlos Augusto Oliveira ${ }^{1}$ \\ Ronaldo Granjeiro ${ }^{2}$ Silvia Cristina Braga² \\ ${ }^{1}$ Department of Otolaryngology, Universidade de Brasília, Brasília, \\ Distrito Federal, Brazil \\ 2 Secretaria de Saúde-Hospital de Base, Brasília, Distrito Federal, Brazil \\ Address for correspondence Lucieny Serra, MSc, Department of \\ Otolaryngology, Universidade de Brasilia, SGAS 604 AV L2 Norte Setor \\ de Saude Auditiva Asa Norte, Brasilia, Distrito Federal 70830200, Brazil \\ (e-mail: lucienymserra@gmail.com).
} Int Arch Otorhinolaryngol 2015;19:171-175.

\begin{abstract}
Introduction Analysis of the suppression effect is a simple method to evaluate cochlear status and central auditory mechanisms and, more specifically, the medial olivocochlear system. This structure may be involved in the generation of mechanisms that cause tinnitus and in the pathophysiology of tinnitus in patients with tinnitus and normal hearing.

Objective To review the literature of the etiology of tinnitus on the lights of otoacoustic emissions in patients with normal hearing.

Data Synthesis Individuals with tinnitus and normal hearing have a higher prevalence of alterations in transient-evoked otoacoustic emissions and distortion-product otoacoustic emissions than normal subjects. This fact suggests that dysfunctions of the outer hair cells (OHCs) might be important in the generation of the tinnitus; however, this feature is not always present in those who have the symptoms of tinnitus.

Keywords

- tinnitus

- organ of Corti/ physiology

- otoacoustic emissions

Final Comments These findings suggest that $\mathrm{OHC}$ dysfunction is not necessary for tinnitus development-that is, there might be mechanisms other than $\mathrm{OHC}$ damage in the tinnitus development. On the other hand, OHC dysfunction alone is not sufficient to cause the symptom, because a great many individuals with $\mathrm{OHC}$ dysfunction did not complain about tinnitus.
\end{abstract}

\section{Introduction}

Tinnitus is a condition in which the individual perceives a sound in the ears or in the head in the absence of outside sounds. A multidisciplinary approach should be used for the treatment of tinnitus as its physiopathology is not fully understood and it seems to be related to disorders of the outer, middle, or inner ears; brain stem; and cerebral cortex. ${ }^{1}$

Individuals with tinnitus frequently report sleep disorders, concentration and attention problems, and symptoms of

received

December 12, 2013

accepted

DOI http://dx.doi.org/

March 6, 2014

published online

June 18, 2014 anxiety and/or depression. These problems can cause difficulties at work and can compromise socialization with family and leisure activities, interfering with social habits and daily dynamics. Each patient is affected differently, irrespective of presence of hearing impairment, and the condition has major negative consequences on quality of life and psychological state. $^{2}$

Tinnitus may be associated with abnormalities in any level of the auditory pathways. However, it starts very often in the

Copyright $\odot 2015$ by Thieme Publicações License terms Ltda, Rio de Janeiro, Brazil

(요 (1) $\Theta \circledast$ 
cochlea. Jastreboff considers that tinnitus usually starts in the cochlea and later generates abnormal activity in the central pathway, which perpetuates the symptom. ${ }^{3}$

Several studies have investigated the relationship between tinnitus and dysfunction of the efferent auditory system by measuring the suppression of otoacoustic emissions (OAEs). Evidence indicates that subtle changes in cochlear function can be detected by OAE testing even before the occurrence of significant changes in the patient's audiogram. ${ }^{4}$ Therefore, the study of OAEs and its suppression are extremely important and have become increasingly necessary for the differential diagnosis of diseases that might cause tinnitus.

This article reviews the literature on OAE testing and suppression of OAEs in patients with normal hearing and tinnitus.

\section{Review of the Literature}

\section{Otoacoustic Emissions}

At the end of the 1970s, Kemp defined OAEs as the release of sound energy produced in the cochlea and its propagation to the middle ear and external acoustic meatus. ${ }^{5}$ The author suggested that these emissions are produced by the outer hair cells (OHCs) of the cochlea as a result of active and nonlinear mechanical feedback processes, which can be spontaneous or evoked by sounds of low and medium intensity. ${ }^{5}$ OAEs are classified as spontaneous or evoked. The latter are divided into transient, distortion-product, or stimulus-frequency OAEs.

Spontaneous otoacoustic emissions (SOAE) are narrowband signals recorded in the ear canal in the absence of an acoustic stimulus, which can be detected in $\sim 50 \%$ of individuals with normal hearing. SOAEs disappear in the frequency range associated with hearing losses that exceed 30-dB HL (hearing level) and are present at normal auditory thresholds. ${ }^{6,7}$ The clinical applicability of SOAEs is restricted because this screening test is of low specificity. In addition, these OAEs may be absent even in individuals with normal middle and inner ear function. ${ }^{8}$

Transient-evoked otoacoustic emissions (TEOAEs) are lowintensity responses produced by the cochlea. These emissions are sound waves emitted after a short acoustic stimulus (clicks or tone bursts) that occur over a wide range of frequencies, thus permitting broad stimulation of the cochlea. ${ }^{7,8}$ TEOAEs can be detected in individuals with normal $\mathrm{OHC}$ function at the frequency analyzed, or in individuals with auditory thresholds below $30-\mathrm{dB}$ HL. TEOAE screening is able to detect impaired hearing but is unable to identify the type and degree of impairment. ${ }^{9,10}$

Like TEOAE, distortion-product otoacoustic emissions (DPOAEs) are sounds generated by OHCs in response to concomitant stimulation with two pure tones (f1 and f2) with closely similar frequencies ( $\mathrm{f} 2 / \mathrm{f} 1=1.22$ ). By convention, the lower-frequency pure tone is referred to as primary $f 1$ and its intensity level is $L 1$. The higher-frequency tone is called $f 2$ and its intensity level is $L 2$. The parameters analyzed in DPOAE testing are amplitude of the signal and signal-to-noise ratio. $^{5,11,12}$ Studies using DPOAEs showed that this type of emission is present in individuals with mild hearing loss of up to $50 \mathrm{~dB}$, depending on the intensity levels used. ${ }^{11,13}$ The advantage of this type of OAE is the greater specificity of the frequency, which permits evaluation of cochlear function from the basal (high frequencies) to the apical (low frequencies) turns by varying the primary frequencies of the evoking stimuli. $^{4,14}$

\section{Effect of Otoacoustic Emission Suppression}

Analysis of the suppression effect is a simple method that permits evaluation of cochlear status and central auditory mechanisms, more specifically, the medial olivocochlear system. ${ }^{15}$ In 1946 , Rasmussen ${ }^{16}$ described the anatomy of the efferent auditory pathway. In the cochlea, efferent control occurs through the olivocochlear system that originates in the superior olivary complex. The system comprises two main bundles, the lateral and medial bundle. The lateral bundle consists of unmyelinated fibers that project ipsilaterally from the lateral region of the superior olivary complex to the inner hair cells. The medial bundle is composed mainly of crossed ( $\sim 80 \%)$ myelinated fibers that originate in the area around the medial superior olive where they directly innervate the OHCs. The olivocochlear system can be activated by electrical or chemical stimulation or noise. Once activated, the system inhibits $\mathrm{OHC}$ contraction, thus reducing the amplitude of OAEs. ${ }^{7,15,17}$ As a consequence, the effect of suppression of evoked OAEs is characterized by a reduction in the response amplitude or by latency and phase changes when a contralateral noise is introduced simultaneously to the recording. ${ }^{18}$

The suppression value is calculated as the difference between the values obtained in the presence and absence of the stimulus. In this respect, a suppression effect is considered to be present when there is a reduction of at least 0.5-dB SPL (sound pressure level) in OAE amplitudes in the presence of a contralateral noise. A suppression effect of 0.5 to 1.0 indicates integrity of the medial olivocochlear system. $^{19,20}$

The presence of a suppression effect in individuals with normal hearing thresholds is a phenomenon reported in a large number of studies. The suppressor stimulus frequently employed is a contralateral broadband noise. However, ipsilateral or simultaneous noise stimuli have been used in different studies. ${ }^{15,21,22}$

\section{Tinnitus Generation Mechanisms}

Many theories describe the generation of tinnitus. In this study, only those that possess direct relationship with the exams of EOA and suppression will be described.

One of the theories for the tinnitus is that it might occur by virtue of the SOAEs (although nowadays this theory is not well accepted). The incidence of tinnitus originated by the SOAEs is frequently uncommon and occurs in less than $10 \%$ of the population with tinnitus. ${ }^{23}$

Another hypothesis for tinnitus refers to the existing disproportional damage between the hair cells. Traumatic situations such as exposure to intense noise or use of ototoxic drugs may cause cochlear damage. These injuries initially occur in the basal portion of the basilar membrane (region of 
high frequencies) and in the outer hair cells (OHCs), following the inner hair cells (IHCs). In this way, it is possible to observe cochlear regions with total lesion of the outer and inner hair cells and other areas of the cochlea with lesion on the OHCs but with unharmed IHCs. The alterations of the mechanic properties of the organ of Corti with lesions on the OHCs produce a tonic depolarization (blocking by depolarization) of the IHCs and the appearance of an irregular activity on the afferent fibers. $^{24,25}$

When there is a lesion of a group of OHCs, a reduction of entrance of the auditory information is observed, provoking diminished efferent activity and inhibition of rapid contractions of the OHCs in this region. Considering that the innervation of the efferent fibers is very diffuse, it is possible that this inhibition affects adjacent healthy regions, causing the hyperactivity of the healthy OHCs perceived as being tinnitus. ${ }^{1,26}$

Granjeiro at the University of Brasilia stated that probably the less efferent inhibition in the ears with tinnitus results from functional characteristics of the efferent system with possible origin on the cochlea or medial olivocochlear system, on the activation of the medial olivocochlear system (MOC system), or with an association of many possibilities. ${ }^{6}$

The medial efferent system influenced by the autonomic nervous system also is another hypothesis, possibly causing oscillations of the symptoms of tinnitus as a consequence of stress, suggesting the presence of parasympathetic activity in the efferent disinhibition. ${ }^{27}$

\section{Discussion}

OAE testing has been used as part of the protocol of audiologic evaluations and is currently an important tool in studies on tinnitus. Tinnitus is a frequently reported symptom, even in patients with normal hearing. A study conducted at the University Hospital of Santa Maria analyzed 480 audiologic evaluations performed between 2005 and 2008 and found normal hearing in $17.08 \%$ and tinnitus in $7.5 \% .{ }^{28} \mathrm{~A}$ significant difference was observed between genders, with a higher prevalence of tinnitus in women. ${ }^{29}$

Several studies have demonstrated a relationship between tinnitus and abnormal OAEs. In a study involving normalhearing patients, TEOAEs and DPOAEs were abnormal in 70.2 and $68.4 \%$ of the group with tinnitus, respectively, but only in 16.10 and $50 \%$ of those without tinnitus. ${ }^{30}$ Similar results have been reported by our research group. We observed abnormal TEOAEs and DPOAEs in 67 and $65.2 \%$ of patients with normal hearing and tinnitus, respectively. ${ }^{31}$

Tinnitus has been suggested to be related to a reduction in the amplitude of OAEs. Fernandes and Santos found a lower amplitude in all frequency bands and in both ears of normalhearing individuals with tinnitus when compared with those without tinnitus. ${ }^{32}$ Mor and Azevedo observed a difference in the cases of unilateral tinnitus, with the overall amplitude being lower in the ear with tinnitus. ${ }^{16}$

The higher prevalence of abnormal OAEs in patients with tinnitus suggests that cochlear dysfunction is involved in the development of this condition, especially at higher frequencies ( 6 and $8 \mathrm{kHz}$ ). ${ }^{30,31,33}$

Studies developed by Maurer and Mann reported another category of individuals in which the otoacoustic emissions were present with greater intensity on the patients with tinnitus and auditory thresholds in the 3,000-, 4,000-, and $5,000-\mathrm{Hz}$ frequencies, suggesting that the tinnitus might be generated by the increase in the motility of the OHCs induced by the diminished activity of the efferent system and not by failure of the OHCs. ${ }^{34}$

According to Azevedo et $\mathrm{al}^{35}$ the auditory perception of tinnitus might be related to dysfunction of the efferent auditory pathway, which would result in the loss of OHC modulation, causing abnormal activity of the auditory pathways that could be wrongly interpreted as sound.

The study of OAE suppression provides reliable information about efferent system function and the interaction between afferent and efferent pathways and also contributes to the differentiation between peripheral and central hearing loss. The absence or reduction in the suppression of OAEs may occur in cases of retrocochlear diseases, auditory neuropathy, acoustic neuroma, impaired auditory processing, and tinnitus. ${ }^{15}$ Studies investigating suppression in individuals with normal hearing and tinnitus have increased in recent years. This fact demonstrates concern regarding the need for a better understanding of the function of the auditory pathway.

Urnau and Tochetto studied normal-hearing adults with tinnitus and hyperacusis and found no association between the suppression effect of TEOAEs and laterality, degree of tinnitus, or degree of hyperacusis. ${ }^{36}$ A study conducted involving a group of normal-hearing individuals with tinnitus showed that the absence of OAE suppression at frequencies of $1.5,2.0,3.0$, and $4.0 \mathrm{~Hz}$ was strongly associated with the presence of tinnitus. The same study demonstrated lower suppression of DPOAEs on the side of perceived tinnitus compared with contralateral suppression. ${ }^{36}$ Another similar study recording suppression of OAEs in individuals with tinnitus and normal hearing concluded that the results were less reproducible in tinnitus patients compared with the control group, but no significant differences in latency or suppression effects were observed between the two groups. ${ }^{33}$

In a recent study conducted in The Netherlands, the authors found no significant differences in the overall analysis of OAE suppression between tinnitus patients and the control group. The suppression value was lower in the right ear of tinnitus patients for the 2.0 - and $2.8-\mathrm{Hz}$ frequency bands but was similar to the control group at the other frequencies. ${ }^{37}$

Azevedo et al investigated the effect of acupuncture on OAEs in tinnitus patients and found an increase in the amplitude and suppression of OAEs after acupuncture treatment, ${ }^{35}$ suggesting that this method exerts an effect on cochlear function. Lower suppression values were also observed in children with impaired central auditory processing when compared with the control group. This finding agrees with the literature showing low or absent suppression of OAEs in cases of cochlear diseases, auditory neuropathies, central auditory processing disorders, and tinnitus. ${ }^{38}$ 
In conclusion, the efferent auditory pathways have been extensively investigated in normal-hearing individuals with tinnitus. However, these studies have not been conclusive and a better understanding of this topic is needed. For this reason, our group has started a new protocol to investigate the effect of OAE suppression in the genesis of tinnitus at our University.

\section{Final Comments}

Based on the previous studies, it is possible to observe that individuals with tinnitus and normal hearing have a higher prevalence of alterations in the exams of TEOAEs and DPOAEs than normal subjects. This fact suggests that dysfunction of the OHCs might be important in the generation of the tinnitus. However, we studied a group of patients complaining about tinnitus and having normal OAE tests. These findings suggest that the $\mathrm{OHC}$ dysfunction is not necessary for tinnitus development-that is, it might be possible that a mechanism other than OHCs is involved in tinnitus development. $^{30,31}$ On the other hand, the OHC dysfunction is not sufficient in itself to cause the symptom, because most individuals with $\mathrm{OHC}$ dysfunction did not complain about tinnitus. $^{30,31}$ In this way, it is important to consider the hypothesis of the involvement of the efferent system in the generation of tinnitus, as well as its analysis by means of the test of suppression of the EOA.

Despite the growing number of publications in recent years, the results of studies investigating tinnitus in normal-hearing patients using OAEs are still inconclusive and further research in this area is needed.

\section{References}

1 Kehrle HM. Relação do incômodo do zumbido com os potenciais evocados auditivos do tronco encefálico e com os transtornos de ansiedade e depressão em indivíduos com limiar auditivo normal [tese]. Brasília: Universidade de Brasília; 2012:179

2 Ferreira LM, Ramos MN, Mendes EP. Caracterização do Zumbido em idosos e possíveis transtornos relacionados. Rev Bras Otorrinolaringol 2009;75(2):249-255

3 Jastreboff PJ. Phantom auditory perception (tinnitus): mechanisms of generation and perception. Neurosci Res 1990;8(4): 221-254

4 Kemp DT. Otoacoustic emissions in perspective. In: Robinette MS, Glattke TJ, eds. Otoacustic Emissions-Clinical Applications. New York, NY: Thieme; 1997:1-21

5 Kemp DT. Stimulated acoustic emissions from within the human auditory system. J Acoust Soc Am 1978;64(5):1386-1391

6 Granjeiro RC. Relação do incômodo do zumbido com a função das células ciliadas externas e os transtornos de ansiedade e depressão em indivíduos com limiar auditivo normal [tese]. Brasília: Universidade de Brasília; 2012:176

7 Bevilacqua MC, Martinez MAN, Balen SA, Pupo AC, Reis ACMB, Frota S. Tratado de Audiologia. 1a ed. São Paulo, Brazil: Editora Santos; 2011

8 Sousa LCA, Piza MRT, Alvarenga KF, Cóser PL. Eletrofisiologia da audição e emissõesotoacústicas-princípios e aplicaçõesclínicas. 1a ed. São Paulo, Brazil: Editora Tecmedd; 2008

9 Stach A. The audiologist's assessment tools. In: Stach A, ed. Clinical Audiology: An Introduction. London, UK: Singular Publishing Group; 2000:292-317
10 Harrison WA, Norton SJ. Characteristics of transient evoked otoacoustic emissions in normal-hearing and hearing-impaired children. Ear Hear 1999;20(1):75-86

11 Probst R, Hauser R. Distortion product otoacoustic emissions in normal and hearing-impaired ears. Am J Otolaryngol 1990;11(4): 236-243

12 Bonfils P, Avan P. Distortion-product otoacoustic emissions. Values for clinical use. Arch Otolaryngol Head Neck Surg 1992;118(10): 1069-1076

13 Azevedo MF. Emissões Otoacústicas. In: Figueiredo MS, ed. Emissões otoacústicas e bera. 1a ed. São Paulo, Brazil: Pulso; 2003

14 Gorga MP, Neely ST, Bergman BM, et al. A comparison of transientevoked and distortion product otoacoustic emissions in normalhearing and hearing-impaired subjects. J Acoust Soc Am 1993; 94(5):2639-2648

15 Leme VN. Emissões otoacústicas: efeito da estimulação acústica contralateral e bilateral na função do sistema auditivo eferente. [dissertação]. São Paulo, Brazil: Universidade de São Paulo; 2009: 121

16 Rasmussen GT. The olivary peduncle and other fiber projections of the superior olivary complex. J Comp Neurol 1946;84(2):141-219

17 Mor R, de Azevedo MF. Emissões otoacústicas e sistema olivococlear medial e pacientes com zumbido e sem perda auditiva. Pro Fono 2005;17(3):283-292

18 Oliveira JRM, Fernandes CF, Costa Filho OA. Study on suppression of otoacoustic emissions: lateral domain. Braz J Otorhinolaryngol 2011;77(5):547-554

19 Collet L, Veuillet E, Bene J, Morgon A. Effects of contralateral white noise on click-evoked emissions in normal and sensorineural ears: towards an exploration of the medial olivocochlear system. Audiology 1992;31(1):1-7

20 Angrisani RMG, Azevedo MF, Pereira LD, Lopes C, Garcia MV. Portadores de vitiligo: estudo das emissões otoacústicas e efeito de supressão. Rev Bras Otorrinolaringol 2009;75(1):111-115

21 Durante AS, Carvallo RM. Contralateral suppression of linear and nonlinear transient evoked otoacoustic emissions in neonates at risk for hearing loss. J Commun Disord 2008;41(1):70-83

22 Ryan S, Kemp DT. The influence of evoking stimulus level on the neural suppression of transient evoked otoacoustic emissions. Hear Res 1996;94(1-2):140-147

23 Kaltenbach JA. Neurophysiologic mechanisms of tinnitus. J Am Acad Audiol 2000;11(3):125-137

24 Samelli AG. Hipóteses Atuais sobre o Zumbido. In: Samelli AG, ed. Zumbido. Avaliação, diagnóstico e reabilitação-abordagens atuais. São Paulo, Brazil: Lovise; 2004

25 Stypulkowski PH. Mechanisms of salicylate ototoxicity. Hear Res 1990;46(1-2):113-145

26 Barreiro-Branco FCA, Knobel KAB, Sanchez TG. Modelo Neurofisiológico do Zumbido. In: Samelli AG, ed. Zumbido: avaliação, diagnóstico e reabilitação. São Paulo, Brazil: Lovise; 1997

27 Hazell JW, Jastreboff PJ. Tinnitus. I: Auditory mechanisms: a model for tinnitus and hearing impairment. J Otolaryngol 1990;19(1): 1-5

28 Urnau D, Silva PAB, Seligman L. Influência do zumbido no índice percentual de reconhecimento de fala em pacientes normoouvintes. Arq Int Otorrinolaringol 2010;14(4):450-455

29 Urnau D, Tochetto TM. Características do zumbido e da hiperacusia em indivíduos normo-ouvintes. Arq Int Otorrinolaringol 2011; 15(4):468-474

30 Granjeiro RC, Kehrle HM, Bezerra RL, Almeida VF, Sampaio AL, Oliveira CA. Transient and distortion product evoked oto-acoustic emissions in normal hearing patients with and without tinnitus. Otolaryngol Head Neck Surg 2008;138(4):502-506

31 Granjeiro RC, Kehrle HM, de Oliveira TS, Sampaio AL, de Oliveira CA. Is the degree of discomfort caused by tinnitus in normalhearing individuals correlated with psychiatric disorders? Otolaryngol Head Neck Surg 2013;148(4):658-663 
32 Fernandes LdaC, Santos TM. Tinnitus and normal hearing: a study on the transient otoacoustic emissions suppression. Braz J Otorhinolaryngol 2009;75(3):414-419

33 Paglialonga A, Del Bo L, Ravazzani P, Tognola G. Quantitative analysis of cochlear active mechanisms in tinnitus subjects with normal hearing sensitivity: multiparametric recording of evoked otoacoustic emissions and contralateral suppression. Auris Nasus Larynx 2010;37(3):291-298

34 Gouveris H, Maurer J, Mann W. DPOAE-grams in patients with acute tonal tinnitus. Otolaryngol Head Neck Surg 2005;132(4):550-553

35 Azevedo RF, Chiari BM, Okada DM, Onishi ET. Efeito da acumpultura sobre as emissões otoacústicas de pacientes com zumbido. Rev Bras Otorrinolaringol 2007;73(5):599-607
36 Urnau D, Tochetto TM. Occurrence and suppression effect of otoacoustic emissions in normal hearing adults with tinnitus and hyperacusis. Braz J Otorhinolaryngol 2012;78(1):87-94

37 Fávero ML, Sanchez TG, Bento RF, Nascimento AF. Supressão contralateral das emissões otoacústicas nos indivíduos com zumbido. Rev Bras Otorrinolaringol 2006;72(2):223-226

38 Geven LI, de Kleine E, Free RH, van Dijk P. Contralateral suppression of otoacoustic emissions in tinnitus patients. Otol Neurotol 2011; 32(2):315-321

39 Ribeiro PS, Torres TL, Starling ALP, Iório MCM, Mancini PC. Crianças com fenilcetonúria: avaliação audiológica básica e supressão das otoemissões. Rev Soc Bras Fonoaudiol 2012;17(3): 248-253 